Published Online on 13 October 2015

Proc Indian Natn Sci Acad $\mathbf{8 1}$ No. 4 September 2015 pp. 1001-1021

(C) Printed in India.

DOI: 10.16943/ptinsa/2015/v81i4/48308

Review Article

\title{
Solar Photovoltaic Energy Harnessing
}

S SUNDAR KUMAR IYER*

Department of Electrical Engineering, Indian Institute of Technology Kanpur, Kanpur 208 016, India

(Received on 20 March 2014; Accepted on 13 August 2015)

\begin{abstract}
There is an urgent need for clean and sustainable methods of power generation to meet the ever increasing demand of energy for human activities. Photovoltaic (PV) technologies are some of the most attractive forms of clean and sustainable power generation. This study introduces the basic PV process and goes on to describe the different solar PV technologies extant today. The strengths and challenges in the deployment of each of the prominent technologies are described. The study concludes by highlighting the government plans for promoting PV and the short, medium and long term initiatives that need to be undertaken in the Indian context for the success of solar PV to harness the sun's energy effectively.
\end{abstract}

Keywords: Photovoltaic Technologies; Solar Cell; Renewable Energy Generation; Sustainable Energy Generation

\section{Introduction}

It is well-established that the quality of life (QoL) often defined or estimated with the help of parameters that are indicative of the general well-being of a population group or country such as employment opportunity, access to health, education level, sociopolitical and economic equality and empowerment, etc. - is strongly dependent on the per capita energy availability. This is especially borne out when the energy availability in a particular country or society is low. Beyond a certain threshold of energy availability, the QoL appears to saturate. This optimal per capita electrical energy availability in industrial and democratic countries for good QoL appears to be around $15-18 \mathrm{kWh}$ of electrical energy per person per day as shown in Fig. 1 (based on data from http:/ /www.eia.gov/ and http://www.economist.com/media/ pdf/QUALITY_OF_LIFE.pdf). The electrical energy available per person per day in India in the beginning of the first decade of the twenty-first century was around 1.5 to $2 \mathrm{kWh}$ per day. It should also be noted that the energy availability is skewed significantly towards the residents in and around urban centres.

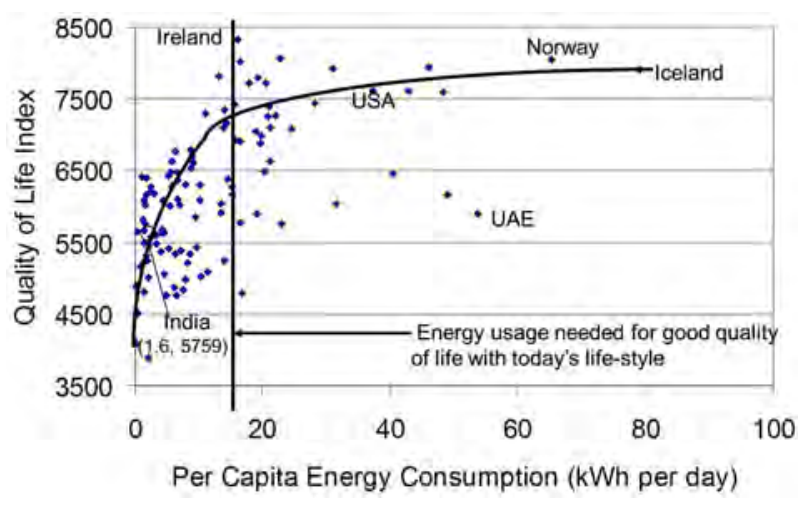

Fig. 1: QoL today has a strong link with the per capita electrical energy available for small values of energy availability. (Plotted with data taken from http:// www.eia.gov/ and http://www.economist.com/media/ pdf/QUALITY_OF_LIFE.pdf)

Thus, to raise the QoL in India for all its citizens, we will need exponential increase in electricity production. As of 2011, India generated 985 billion $\mathrm{kWh}$ of electricity (http://www.eia.gov/) and by the yardstick of maximizing QoL for all citizens, 6000 billion $\mathrm{kWh}$ needs to be generated - an almost six-fold increase in power generation. Relying purely on fossil fuels

*Authorfor Correspondence: E-mail: sskiyer@iitk.ac.in 
might be counter-productive economically and environmentally and one needs to explore renewable sources. Among the various renewable sources of energy, tapping solar energy directly with photovoltaic (PV) technology is an attractive and practical option, especially for a country such as India which received abundant sunshine for most of the year.

Approximately $170 \mathrm{PW}\left(\mathrm{P} \equiv\right.$ peta $\left.\equiv 10^{15}\right)$ is incident on the face of the earth at any point of time, which is 6000 times more than the current world demand of $17 \mathrm{TW}$ of energy used - out of which electricity generation is around $2.3 \mathrm{TW}$. The total energy demand is expected to increase to $30 \mathrm{TW}$ by the middle of this century (Hoffert et al., 1998).

The electricity production in India as of 2011 was $112 \mathrm{GW}$ (985 billion $\mathrm{kWh}$ per year), which is about $5 \%$ of the total world energy production (http:/ /www.eia.gov/). As seen in the solar insolation map of the Ministry of New and Renewable Energy (MNRE), Government of India (Fig. 2) (http://

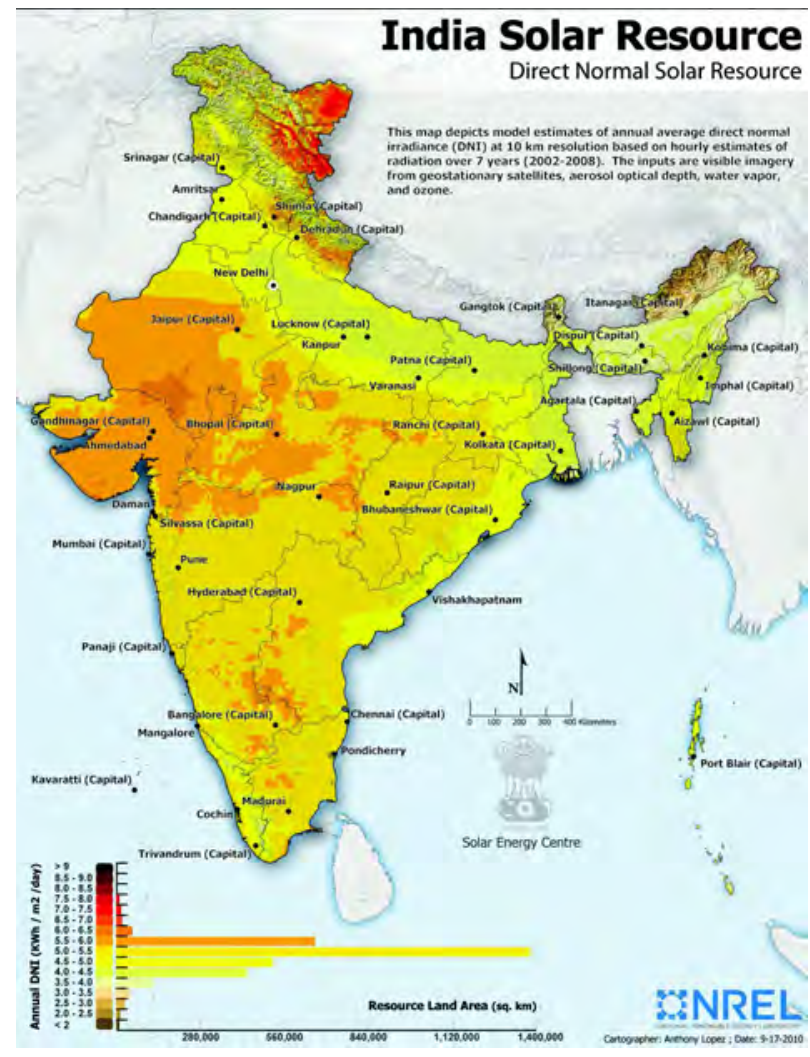

Fig. 2: Annual average energy that can be generated per $\mathbf{m}^{2}$ per day for India. (http://www.mnre.gov.in/sec/solarassmnt.htm) www.mnre.gov.in/sec/solar-assmnt.htm), most parts of India receive more than $5 \mathrm{~kW} \times \mathrm{m}^{-2} \times$ day. Even with $10 \%$ efficient PV power generation, India's current electricity requirement can be generated in an area less than $75 \mathrm{~km} \times 75 \mathrm{~km}$ which is less than $1 \%$ of its land area. This deployment should, of course, be distributed to take advantages of its inherent strength and also to minimize transmission losses. The capital involved in the deployment of so many PV panels and their availability will be a bottle neck - besides the challenge of storage of energy for use at night when PV panels cannot generate power. However simplistic this calculation might appear, it helps us realize that with availability of the right technology and policies, India is well-placed to generate a significant fraction of its energy requirement directly from incident solar radiation.

While the solar power may be tapped by various means such as solar thermal and photochemical approaches, PV allows for direction conversion to electricity which has evolved to be the most convenient form of energy for human use. The other approaches too have their advantages (as discussed in the other contributions in this volume), and one should evolve methods of combining the different approaches for effectively harnessing solar power for human use. We will focus on the current status of PV technologies, the challenges and opportunities these provide in tapping solar power and finally discuss possible approaches of deploying them effectively, especially in the Indian context.

\section{Brief History and Status of PV Deployment}

While the photovoltaic process was described and some of its aspects were understood in the 19th century, especially by Alexandre-Edmond Becquerel, it was in 1952 that the first solar cell with more than $1 \%$ efficiency was demonstrated in Bell Labs by Chapin, Fuller and Pearson (Chapin et al., 1954). Their cell fabricated with a $p$ - $n$ junction on Czochralski process grown monocrystalline silicon had an efficiency of $6 \%$. The news of its fabrication was received with much enthusiasm by the press and the scientific community. Within a couple of decades, PV established itself as an important and mature 
technology for power generation, especially in niche applications such as power generation in space, remote locations and in consumer electronics. However, its use for large-scale power generation replacing the use of fossil fuels did not happen due to the higher cost in the fabrication of the solar cells as well as the huge energy payback time for the solar cells fabricated with the existing technologies.

There was a big push to promote renewable power including PV in the decade of the 1970s, especially in USA and other western countries due to the unavailability of petroleum. In India too, in that decade, the existing research institutes of the time were involved in PV research and development. However, with the political and economic resolution of the issues with oil producing nations and the supply of petroleum becoming more abundant, the emphasis on PV research was reduced - although it did not stop but continued only in low key. It was only in the first decade of the 21st century that the emphasis on PV research has come back, especially in the context of growing awareness of global warming due to continued use of fossil fuels. Owing to government incentives in countries such as Germany, PV manufacturing has taken off rapidly in the last decade and the cost of solar PV power is quickly moving towards grid parity making it more and more competitive.

\section{Components in the Deployment of PV Technology}

The components that need to be handled for the deployment of solar PV power generation technology consists of the following: (i) power generation; (ii) power electronic system and (iii) a load or a storage where the generated power may be used up immediately or stored as energy for future use.

\section{Power Generation}

Electrical power is generated from solar insolation with the help of solar modules which are implemented by a range of technologies. These technologies are at various stages of maturity and development, which offer various trade-off in cost, efficiency, stability, weight and aesthetics. The most popular technology is based on silicon - both single crystalline and multicrystalline. However, due to the high cost per watt of energy with these PV cells, various thin film silicon have emerged. Some of the more popular technologies in this category are cadmium telluride (CdTe) and copper indium gallium diselenide/sulphide (CIGS). Another promising technology, especially in the Indian context is amorphous silicon solar cells and their variations. In recent years, a variety of promising technologies have emerged including dye-sensitized solar cells, organic solar cells and quantum dot solar cells. The high efficiency compound semiconductorbased cells and multi-junction solar cells have also made rapid strides in recent years. Often the costly, but high efficiency solar cells are used with concentrators, where the mirrors which are cheaper than the high efficiency cells collect sunlight from a wider area and concentrate on to a small area.

The choice of the technology to be deployed will depend on the specific application, availability of land and the capital cost restrictions. The current status of many of these technologies and the challenges they face will be discussed in more detail in section - $P V$ Technologies for PV Power Generation.

\section{Power Electronic System}

Once the charges have been separated and the PV process is complete in the $\mathrm{PV}$ cell/module, the power needs to be extracted to the outside world efficiently for practical use. The power extracted will be a maximum only for a particular load value as seen by the photovoltaic cell/module. It is possible to build electronic circuits that can track the $I$ - $V$ characteristics of the PV cell/module and help extract maximum power from the module. Such circuits are called maximum power point tracking (MPPT) circuits and are to be designed for the specific solar module technology and system as well as the load to which the power is to be actually delivered. Besides the power extraction from the power generating cell/ module, the power electronic system also balances the variations in power from the different modules as well as the specific requirements of the load which might be a battery bank where energy is stored or a grid to which the generated power is immediately evacuated. The power system has to be custom built 
according to the specific location and purpose of the PV system. The Indian grid system's features are distinct from those in developed countries. The weather and maintenance conditions possible in the places where the PV deployment is taking place may also vary. These have to be also factored in when putting together a power electronic system. In the Indian context, location-specific power electronic system design and deployment is a critical factor in the successful deployment of PV technology.

\section{Energy Storage}

The power harnessed by a solar PV system and provided as electrical power could be immediately used up by supplying to the grid or it has to be stored as energy, possibly with the help of batteries. This is unlike the solar thermal and solar chemical routes for harnessing solar power where the harnessed energy is automatically stored in the steam generated or as chemical energy which could be used after a gap in time.

For solar PV, directly supplying the power generated to the grid is increasingly popular. This is particularly attractive if the peak power demands coincide with the power generation periods during the day. This solution may be acceptable today when power generated and fed to the grid is a small fraction of the fossil-dominated power generation. When the main source of power in a grid is from PV, stability of the grid can be captive to the vagaries of the power generation due to the availability of sunshine and its variation during the day. In systems and situations where the generated power from PV needs to used later (e.g. at night when sunlight is not available), it is important to evolve low-cost, economically viable and environment-friendly methods of energy storage. This could take the form of storing water in elevated reservoirs, or electro-chemical methods such as batteries or with hydrogen fuel cells.

The storage duration required may be: short term to ease of transfer of power to the grid and to protect output power from momentary fluctuations, possibly due to a bird flying over the panel or cloud momentary covering the sun or other causes; medium term to take care of hourly variations in solar PV power generation as the sun moves across the sky or a few hours of cloudy weather; or long term to manage seasonal variations in $\mathrm{PV}$ power generation and longer periods of lack of sun as during monsoons or foggy winter months. For the success of large-scale PV technology deployment and to effectively use the technology, it is critical to address storage methods that are economical and compatible to PV technologies.

While all three aspects - power generation, power electronic system and energy storage discussed in the above three sub-sections - Power Generation to Energy Storage are important for deployment of PV power generation technology, we will focus on power generation with PV. The other aspects are discussed elsewhere in this volume.

\section{Photovoltaic Action and Power Generation Efficiency}

Photovoltaic action may be divided into three steps: (i) absorption of incident photon; (ii) creation of an electron-hole pair that can conduct current; and finally (iii) separation of this electron and hole to separate electrodes to create the electro-motive force (emf) of the PV cell as a power source.

\section{Absorption of Incident Light}

The intensity of incident light drops exponentially in a material as it goes through it. This is modelled by the Beer-Lambert's law (Swinehert, 1962):

$$
I(x, \lambda)=I_{0}(\lambda) \cdot \exp [-\alpha(\lambda) \cdot x],
$$

where $I_{0}(\lambda)$ is the intensity of the incident optical beam of wavelength $l$ and $I(x, \lambda)$ is the intensity of beam after it travels a distance $x$ from the surface within the material. Here, $\alpha(\lambda)$ is the absorption coefficient in the material for light of wavelength $\lambda$. For photovoltaic material, we would want $\alpha(\lambda)$ to be large for the $\lambda \mathrm{s}$ present in the solar spectrum. Thus, less material will be sufficient to absorb the photons coming in from the sunlight to contribute to the PV process.

\section{Creation of Electron Hole Pairs}

An incident photon in a material can be absorbed provided an electron can absorb its energy and is able 
to find an energy state in the electronic band structure that can accommodate the excited electron. For example, in the schematic shown in Fig. 3, any electron in the filled valance band can absorb energy in the range of $E_{\mathrm{m}}<E<E_{\mathrm{g}}$. Thus, the absorption coefficient $a(l)$ depends on the band-gap, besides the electronic band structure of the material. For indirect band-gap semiconductors such as silicon, the non-zero change in momentum has to be accommodated with the involvement of phonons which makes the absorption less probable. This is why for indirect band-gap semiconductors, the absorption coefficient is small.

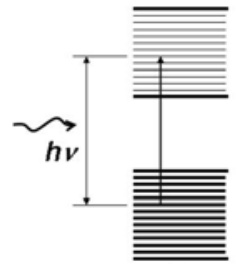

A

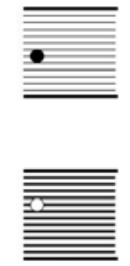

B

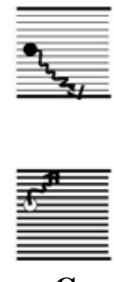

C

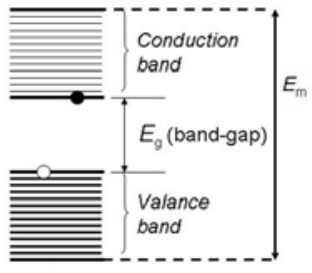

D
Fig. 3: Incident photon of energy $h v>E g$ (band-gap) A: Excites an electron from the valance band to conduction band, which results in, B: An excited electron and an excited hole. C: The excited charges thermalize in a short time to come to the bottom of conduction band and top of the valance band, respectively. $D$ : The free electron and hole now need to be separated physically which is usually accomplished with the help of a built-in electric field to create an emf in the solar cell

Once the photon energy is absorbed by the electron to form the electron-hole pair, they thermalize rapidly. The electron comes to the lowest possible state in the conduction band and the hole to the highest possible state in the valance band. This change in energy in the electron and hole is dissipated as heat.

\section{Physical Separation of Electrons and Holes}

The thermalized electron and hole now need to be physically separated. This is usually achieved by a built-in field present in the device at the location of the formation of the electron-hole pair. The most popular way of achieving the built-in field is by creating a $p-n$ junction in a semiconductor. The electron gets swept towards the cathode and the hole gets swept towards the anode. This separation of charge creates an emf in the solar cell which can do useful work on an external load connected across the PV cell terminals.

\section{Efficiency of a PV Cell}

The power conversion efficiency of a PV cell for comparative purposes is determined by exposing the cell/module to a known intensity of optical radiation of a given spectrum. The maximum electrical power that can be extracted from the cell by choosing the appropriate load, is then determined and this is taken to be the useful electrical power generated. This latter quantity may be expressed as the product of $V_{\text {oc }}$, the open circuit voltage obtained in the PV cell, $I_{\mathrm{sc}}$, the short circuit current for the PV cells and the fill factor (FF). The FF is a fraction of the maximum power that can be extracted by an optimum external load from the solar cell to the product of $V_{\mathrm{oc}}$ and $I_{\mathrm{sc}}$. (For more information on FF, please refer to the article by Saha et al. in this Special Issue of INSA on Energy.) Thus, the power conversion efficiency $(\eta)$ in the solar cell for an incident power of $P_{\text {in }}$ is given by

$$
\eta=\left(V_{\mathrm{OC}} \times I_{\mathrm{SC}} \times \mathrm{FF}\right) / P_{\mathrm{in}},
$$

where $\eta$ may often be expressed as a percentage.

\section{Sun's Spectrum and Units Specific to Solar Cells and Modules}

When a photovoltaic cell is used for generation of power from solar irradiation, it is often referred to as a solar cell and the module built with it is called a solar module. Thus, solar cells and modules for terrestrial applications need to be calibrated to the sun's spectrum on the earth's surface. The rating of the solar cells and modules are also made with distinct units which are described here.

\section{The Solar Spectrum}

The energy from the sun reaches the earth in the form of solar irradiation. The incident power is distributed over different wavelengths. The spectrum observed corresponds to a black-body radiation at $6000^{\circ} \mathrm{C}$, which is the temperature of the sun on its surface. The radiation from the sun reaches earth located approximately 8.32 light minutes away. Just 
outside the earth's atmosphere, the total intensity of light is $1353 \mathrm{~W} \mathrm{~m}^{-2}$ (Sze, 1991). When the light reaches the earth's surface, not only does its intensity get attenuated, but its spectrum also gets altered. This is due to the absorption of sunlight as it passes through the atmosphere to reach the earth's surface. Thus, depending on the distance in the atmosphere that the light travels, which in turn depends on the sun's position with respect to the zenith, the spectrum and intensity of light reaching that location on the earth's surface varies.

When the sun is overhead, solar irradiation travels through one atmosphere length before reaching earth's surface. The spectrum corresponding to this is called AM1.0. When the sun is about midway to the zenith from the horizon (more accurately at $48.19^{\circ}$ ), the sun's radiation traverses 1.5 times the thickness of the atmosphere and the spectrum is called AM1.5 (Fig. 4). This spectrum is considered as the average of the sun's radiation during the day as it moves from the horizon at sunrise $\left(90^{\circ}\right)$ to the zenith position during midday $\left(0^{\circ}\right)$ and finally again at the horizon at sunset $\left(90^{\circ}\right)$. Moreover, solar spectrum gets modified depending on whether direct sunlight is considered or scattered light is also taken into consideration. This modification in spectrum is indicated with a G for "global" or D for "direct".

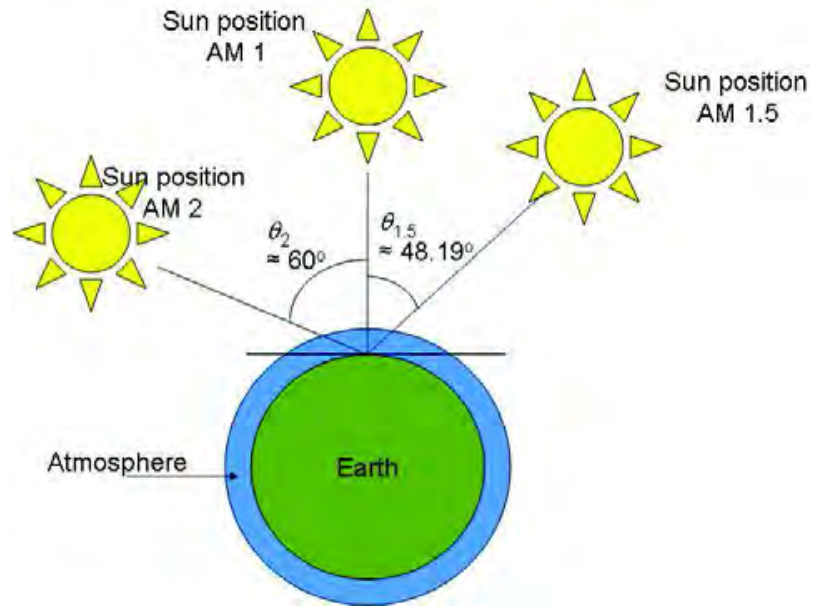

Fig. 4: Spectrum of the sunlight reaching the earth's surface is modified by the distance the sunlight has to travel through the atmosphere depending on the sun's position with respect to the zenith. AM1.5 G is taken as the spectrum to calibrate solar cells and modules

\section{Rating and Output of a Solar Cell/panel}

For terrestrial applications, the internationally accepted standard is to calibrate all solar cells and panels at $25^{\circ} \mathrm{C}$ for a spectrum of AM1.5 G with a light intensity (integration of the intensity of light for all the wavelengths) of $1000 \mathrm{~W} \times \mathrm{m}^{-2}\left(100 \mathrm{~mW} \times \mathrm{cm}^{-2}\right)$ as shown in Fig. 5. This intensity of light is also often referred to as 1 sun intensity. The maximum electrical power that can be garnered from the solar panel for this standard illumination (AM1.5G spectrum with 1 sun intensity) is referred to as the watt peak (Wp) rating of the solar panel.

There are, however, variations in the intensity and spectrum of light that reaches different locations on earth depending on the latitude, altitude, local weather and atmospheric conditions and the immediate surroundings of the solar panel. For example, a $1 \mathrm{Wp}$ (watt peak) in the higher latitude might be able to generate less than $3 \mathrm{Wh}$ in a period of one day in winter, while the same panel in a desert region located near the Tropic of Cancer might generate more than $6 \mathrm{Wp}$ during a long summer day. Thus, the size of the solar panels in terms of $\mathrm{Wp}$ that will need to be installed for generating the required energy will depend on the exact location of their deployment.

India, by virtue of its location is blessed with sunlight for most of the year. On average, over the year, most parts of the country can generate 5 to 6 Wh of energy from a $1 \mathrm{Wp}$ solar panel (Fig. 2). During rainy season and in foggy winter months in some parts of the country, the energy that can be harnessed might decrease to much lower values. More details for specific locations in India can be obtained from the MNRE, Government of India website (http:// www.mnre.gov.in/sec/solar-assmnt.htm).

\section{Shockley-Queisser Limit for Solar Cell Materials}

As seen earlier in section - Creation of Electron Hole Pair a material with a band-gap $E_{\mathrm{g}}$ will absorb only the part of the spectrum with energy greater than $E_{\mathrm{g}}$. Moreover, energy more than $E_{\mathrm{g}}$ that is absorbed from the photon is lost as heat during thermalization. Thus, only a limited part of the spectrum of the sun's radiation 


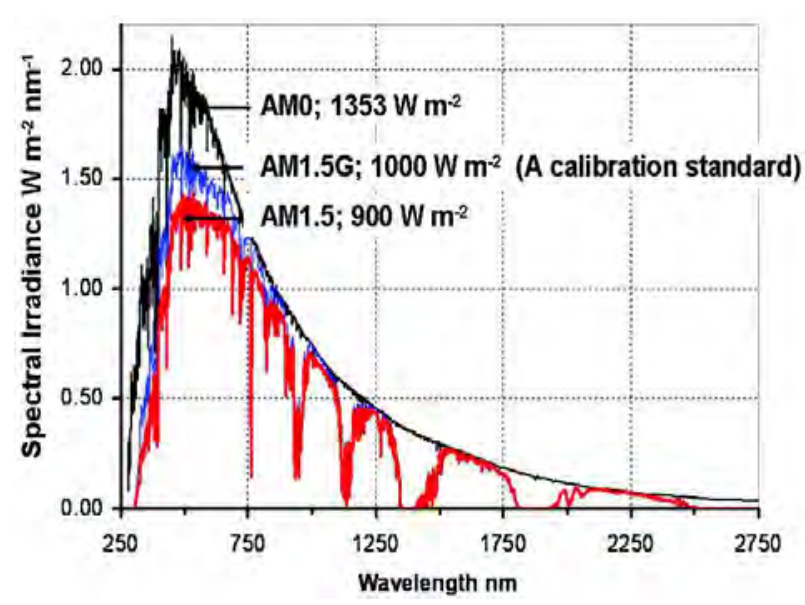

Fig. 5: Solar spectrum and intensity for AM0 (just outside the atmosphere) and for AM1.5 when the sun is at 48.19 $^{\circ}$ to the zenith (http://rredc.nrel.gov/solar/ spectra/)

and only a part of the absorbed energy will be useful during the photovoltaic process to generate the emf in the solar cell. Based on a detailed thermodynamic argument by Shockley and Queisser, the upper bound of efficiency for solar cells built with materials of a given band-gap can be estimated (Shockley and Queisser, 1961). This efficiency bound is known as the Shokley-Queisser limit (Fig. 6). The fundamental losses are due to inability of semiconductor to capture photons with energy less than the band-gap; thermalization loss in the electron-hole created with energy larger than the band-gap; Boltzmann loss; and Carnot loss (Hirst and Ekins-Daukes, 2011).

However, this upper bound may be extended beyond the Shockley-Queisser limit by building multi-

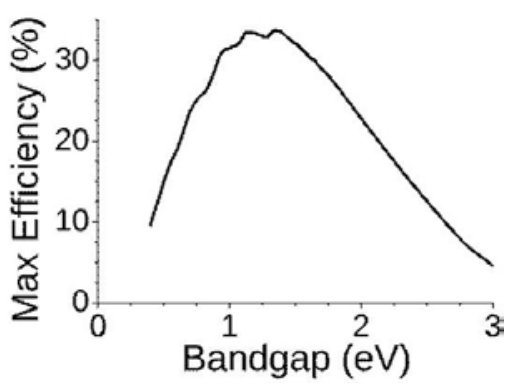

Fig. 6: Upper bound of efficiency of a single junction solar cell with a material of a given band-gap is called the Shockley-Queisser limit after the scientists who proposed it (Shockley and Queisser, 1961) junction or tandem cells, i.e., solar cells built one above the other so that the lower cells absorb the spectrum of light not collected by the cells above. Efficiency may increase in a well-designed system due to the lowering of thermalization loss in the individual solar cells. The theoretical limit of upper bound of efficiency has been determined by Alexis De Vos (De Vos, 1980). When two or more cells with varying bandgap materials are used, the upper bound efficiency can be increased significantly. For unconcentrated incident sunlight with a large (infinite in theory) number of cells stacked in series on top of each other, the upper bound of efficiency is $68 \%$ and for concentrated sunlight, the upper bound is as high as $86 \%$. Concentration of light helps increasing the open circuit voltage as well as the short circuit current which can result in generation of more electrical power to increase incident photons, provided the gain is not offset by too much rise in temperature or recombination of excess carrier within the cell.

From a practical point of view, however, it is to be noted that building tandem cells can be costly and a design ensuring the same current through all the tandem cells connected in series can be difficult and will be valid only for a particular relative position of the sun with respect to the zenith as the spectrum of sunlight changes with the sun's location in the sky. Similarly, using concentrators will require extra care in tracking the sun and ensuring that the cell temperature does not become unacceptably high. All the same, these calculations are useful as they give the upper bound of efficiency for solar cell designers and fabricators. They may be pursued in situations where cost consideration is not a limiting factor for generating power, for example, in the context of space exploration.

\section{PV Technologies for PV Power Generation}

A snapshot of the various technologies is provided in Fig. 7 which shows the "Best Research-Cell Efficiencies" being compiled and updated by the National Renewable Energy Laboratories in Golden Colorado (http://www.nrel.gov/ncpv/images/ efficiency_chart.jpg). The solar PV technologies available today may be broadly classified in the 


\section{Best Research-Cell Efficiencies}

\section{SNREL}

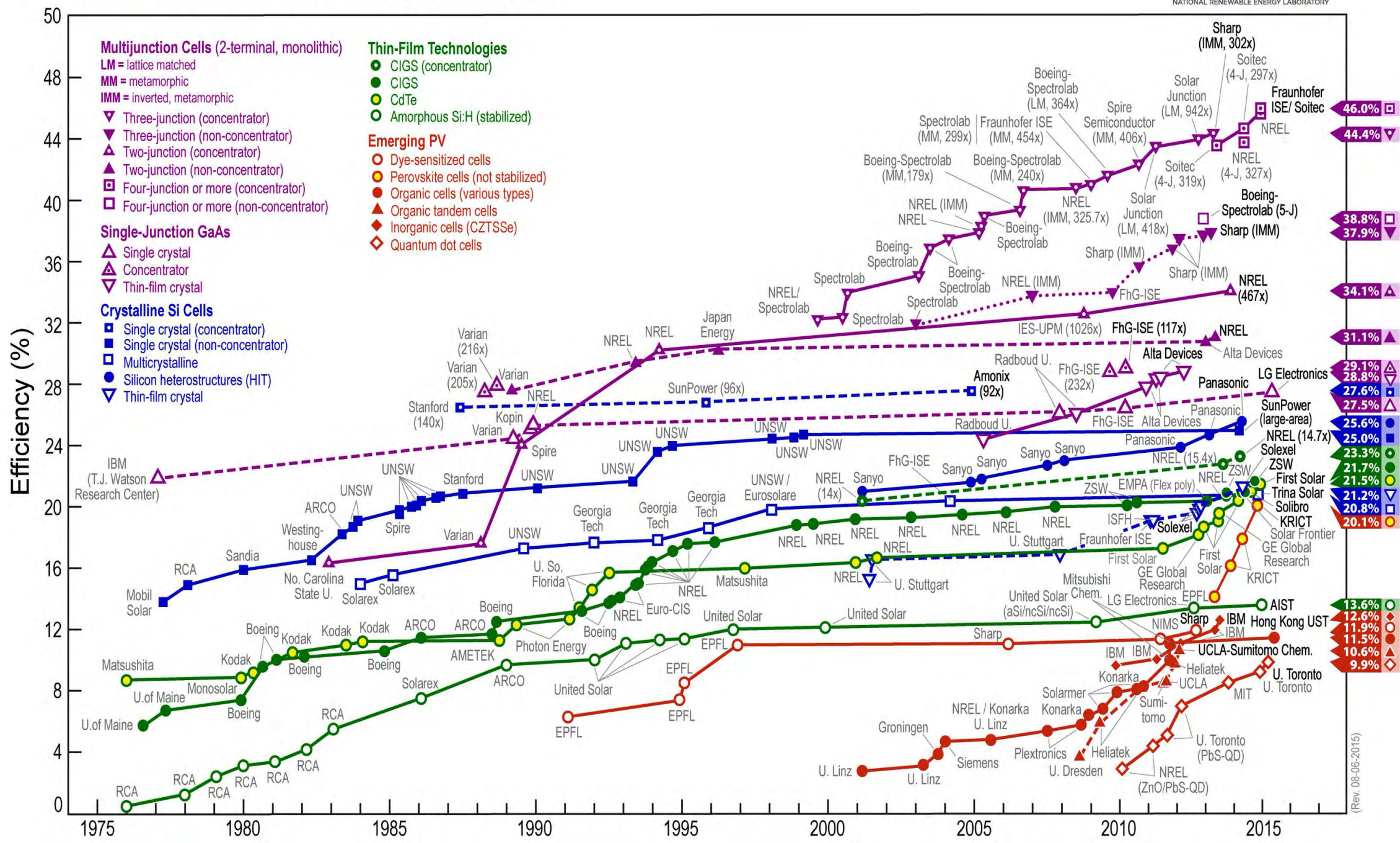

Fig. 7: Plot of compiled values of highest confirmed conversion efficiencies for research cells, from 1976 to August 2015 . This plot is obtained by courtesy of the National Renewable Energy Laboratory, Golden, Colorado, USA (http://www.nrel.gov/ncpv/images/efficiency_chart.jpg) 
following categories: (i) silicon-based solar cells (first generation); (ii) thin film inorganic semiconductor including amorphous $\mathrm{Si}$, CIGS and CdTe solar cells (second generation); (iii) higher efficiency compound semiconductor solar cells such as GaAs and multijunction solar cells (third generation) and (iv) newer and futuristic technologies in solar cells such as organic, dye-sensitized solar cell (DSSC) and quantum dot solar cells (also classified as third generation). The advantages and challenges of popular solar cell technologies are presented here.

\section{Silicon-single Crystalline and Multi/polycrystalline}

Silicon is one of the best understood materials, owing to the immense research and development in the very large-scale integration (VLSI) industry where silicon technology is the mainstay. Moreover, the abundance of silicon on earth's crust makes it attractive when one envisions building solar cells in large volumes that can produce terawatts of power needed in the future.

The mainstay of solar cells till date has been silicon solar technology. In this technology, scientists have managed to prepare solar cells on silicon substrates with efficiency close to the maximum possible $25 \%$ for single junction cells on $\mathrm{Si}$, as predicted by the Shokley-Queisser limit and assuming the best attainable values of material properties with today's technologies (Zhao et al., 1998).

The cost of manufacturing a silicon solar module consists of broadly three components - the material cost which is primarily the silicon wafer cost, the cost of processing the wafer and the cost of building the module with the wafers. There has been a constant effort in the industry to reduce all these components of cost, while not adversely affecting the efficiency of the solar module. One of the approaches to reduce the material cost is to simply reduce the amount of silicon used to build the solar cells (thin-film silicon solar cells). This may take the form of poly or multicrystalline solar cells that are formed by lower cost process compared to the costly Czochralski process. Another approach is to use amorphous silicon to build solar cells as discussed in the next sub-section. The lower cost material, often result in lowering of the overall efficiency of the solar module built. Fig. 8

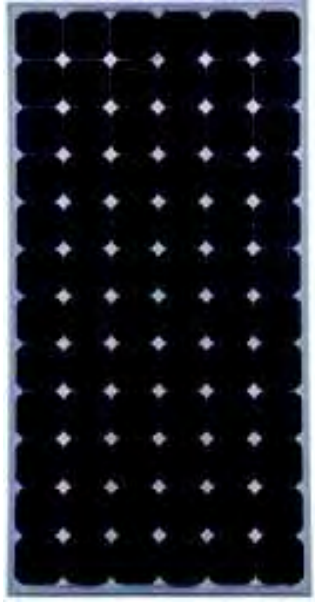

A

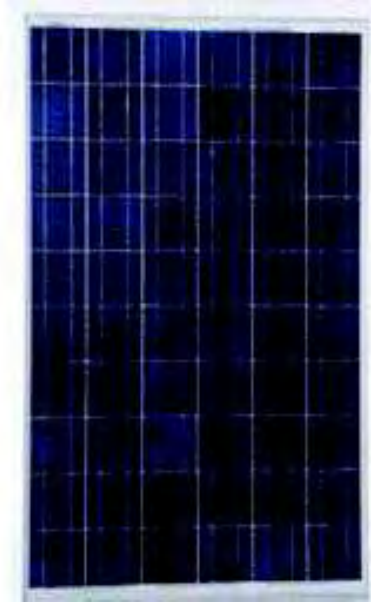

$\mathbf{B}$
Fig. 8: A: Module built with single crystalline solar cells; and B: A module built with multi-crystalline solar cells. (http://solarmaxdirect.com/)

shows examples of single crystalline and multicrystalline modules. The former modules are often immediately identifiable by the gaps between the cells in the module - the single crystalline cells being made with circular wafers which are often optimally chamfered to increase the packing density while minimizing the wastage of high quality single crystalline substrate.

Yet another approach to reduce cost of material used in the solar cell is to use 'solar grade' silicon rather than the "electronic grade" silicon (Solanki, 2011). In the past, the lower grade silicon that was left over after supplying to the VLSI industry was sufficient to supply manufacturers of silicon PV modules. The VLSI industry has stringent requirements about impurity contents such as Fe, Al and other metals. Electronic grade silicon would need impurity levels of less than parts per billion. On the other hand, wafers with lesser purity might be agreeable for solar cell fabrication with acceptable performance. These 'parts per million' purity solar grade wafers incur significantly lower costs. In recent years, since the boom in PV production, the volume of silicon used to build solar cells is exceeding that used for VLSI chip production. Many plants for solar grade silicon have been set up, especially in China, which have flooded the market and have brought down 
prices of silicon wafers to unprecedented levels.

Even with solar grade wafers, prices can be brought down further if the wastage during the sawing of ingots could be minimized (Goetzberger et al., 2003). Typically, almost $50 \%$ of the ingot may be lost due to "kerf" losses. Some have tried to remedy this by preparing kerfless silicon wafers. Two of the popular methods used are edge-defined film-fed growth (EFG) and string ribbon silicon technologies. In the case of EFG, Si-wafers are pulled out from the melt by using graphite die with capillary action. ASE Americas are primarily responsible for this technology. One may also pull out the wafers with a pair of high temperature wires from a silicon melt. This process was championed by Evergreen Solar (http:// www.evergreensolar.com/en/about/).

To reduce the cost even further, ultrathin silicon technology is being pursued where 5 to $50 \mathrm{~mm}$ thick wafers are fabricated. Simulation results from Martin Green show that you can obtain $19.8 \%$ efficiency solar cells with $1 \mathrm{~mm}$ thick silicon solar cells although some touch up processing will be needed on these thinner wafers (Green, 1999). The traditional assumption was that you need more than $100 \mathrm{~mm}$ silicon wafers to be able to absorb sufficient light due to the indirect band-gap in the material - but the fractional higher efficiency one gets will come at a cost. So, these ultrathin silicon wafers, if successfully made and handled during fabrication, can bring down the cost of material by an order of magnitude. One of the interesting ways of preparing ultra-thin wafers is by cleaving the wafers at the edge, a process pioneered by Silicon Genesis and called as the PolyMax ${ }^{\mathrm{TM}}$ process. This is a kerfless technology which makes it competitive with much potential.

Besides reducing material cost, novel modifications are continuously attempted by silicon manufactures such as printing of the contacts (Hilali et al., 2004) or ion implantation (Rohatgi et al., 2012) in order to reduce the processing cost and time. Use of backside contact by SunPower to avoid shadowing effects (Mulligan and Swanson, 2003), anti-reflection coating (Rowlette and Wolden, 2009) and plasmonic techniques (Atwater and Polman, 2010), especially in thin silicon wafers (also common to other PV technologies), are some of the processing tricks used by various manufacturers to increase the efficiency of solar cells. A good reference on issues related to silicon PV can be found in Goetzberger et al. (2003).

Internationally, the whole manufacturing of silicon solar cells has shifted to China due to the ability of the industries to produce cells and modules at low cost. In spite of tariffs imposed on Chinese solar products by other countries, they remain competitive to the products manufactured in the USA and Europe. In India, there are a few companies such as Lanco Solar in Rajnandgaon, Chhattisgarh and Moser Baer in Greater Noida in Uttar Pradesh that engage in panel assembly. However, there is no wafer to module type integration or manufacture today in India. Some research activities are being carried out in IIT Bombay in the Microelectronics Centre and the National Centre for Photovoltaic Research in crystalline silicon PV technology. National Physical Laboratories, New Delhi is also researching various methods to improve silicon PV efficiencies. Central Glass and Ceramics Research Institute, Calcutta and other CSIR labs are also looking into developing materials for improved light harvesting for silicon (and other) PV technologies.

\section{Silicon-amorphous and Nano-crystalline}

Amorphous silicon solar cells are simpler to fabricate since the solar module is directly fabricated on the substrate with amorphous silicon deposition being one of the intermediate steps. The maximum temperature of processing is typically $450^{\circ} \mathrm{C}$ and often lower making it especially attractive for solar cells implementation on flexible substrates and for light weight building integrated PV (BIPV). The deposition is carried out using hydrogen $\left(\mathrm{H}_{2}\right)$ and silane $\left(\mathrm{SiH}_{4}\right)$ gases by the plasma enhanced chemical vapour deposition (PECVD) process - which is the most popular method in commercial use. Since the doping of the amorphous silicon causes decrease in lifetime of carriers, usually, $p-i-n$ structure is used in this technology with the absorption of light taking place in the lightly doped intrinsic region. Since the first demonstration of this technology in 1976 (Carlson and Wronski, 1976), buoyed by prevalence of the deposition process in the VLSI industry, it made rapid progress; 
and by 1980 , more than $10 \%$ of the efficient cells found commercial application. However, this technology was soon plagued by instability in the efficiency - known as the Staebler-Wronski effect (Staebler and Wronski, 1977). The passivating hydrogen moves with time resulting in drops in efficiency which stabilizes around 6-7\%. Due to its lower efficiencies, amorphous silicon modules are usually popular for portable and distributed power generation (Fig. 9).
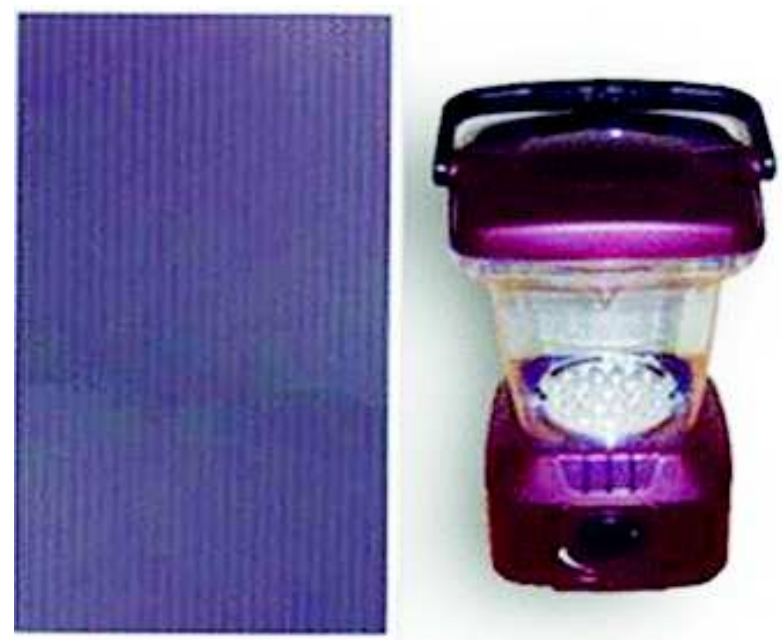

Fig. 9: An example of an amorphous silicon module along with a solar lantern (http://www.solar-global.cn)

One way to avoid this drop in efficiency due to Staebler-Wronski effect is to build amorphous silicon - nanocrystalline silicon (aSi-ncSi) multi-junction stacks. The nc-Si is more stable and can be achieved by increasing hydrogen concentration during the PECVD deposition. However, the deposition process is significantly slowed due to this (Roschek et al., 2002).

Internationally, this technology seems to have peaked and is on the wane, at least temporarily. However, in the Indian context, the low cost of fabrication of these cells might still make it attractive for many applications, such as portable PV and for BIPV. Also, the use of plasmonics and other photon management techniques might help extract better efficiencies and lower costs for the power produced.
In India, Bharat Heavy Electrical Limited (BHEL) has set up an Amorphous Silicon Solar Cell Plant (ASSCP) at Gwal Pahari, Gurgaon. Research and development in amorphous silicon is being carried out by Indian Institute of Engineering Science and Technology at Shibpur, Jadavpur University and Hind Hivac Ltd. Many private research institutes such as SSN Research Centre located in south Madras are also working to develop amorphous silicon solar cells.

\section{HIT Cells - Amorphous and Single Crystalline}

The combination of crystalline silicon with amorphous $\mathrm{Si}$ - popularly referred to as heterojunction with intrinsic thin layer (HIT) cells - is increasing attractive to supplement the efficiency of single crystalline silicon PV cells with marginally increased processing cost. The aSi/cSi heterojunction cells with intrinsic layer, have achieved record efficiencies of more than $21 \%$. There are many variations of the HIT cells with $n$ type or $p$-type a-Si, for example, those developed at Sanyo (Taguchi et al., 2005) and EPFL, Neuchatel (Hänni et al., 2013). In India, BHEL in Gurgaon has also managed to demonstrate structures similar to HIT cells successfully.

\section{Copper Indium Gallium Diselenide/sulphide}

In its earlier version, the thin film solar cells with efficiencies of around $6 \%$ to $7 \%$ were demonstrated with $\mathrm{CuInSe}_{2}$ by Kazmerski et al. (1976). This material combination had a band-gap of around $1 \mathrm{eV}$. It was found that the band-gap could be tuned by substituting $\mathrm{Ga}$ in place of In and $\mathrm{S}$ in place of Se from $1 \mathrm{eV}$ to $2.5 \mathrm{eV}$ - giving rise to CIGS. Depending on the process and the group fabricating it, the actual absorption layer may contain four or five elements. There was rapid progress in 1990s in this technology and best cells with efficiencies of $16 \%$ were demonstrated. Unlike many other technologies, CIGS efficiencies have shown a steady climb over the years in performance and devices with efficiencies of more than $20 \%$ efficiencies have been demonstrated recently. The potential for further improvement makes this technology very promising. Since 2007, production capacities of many tens of MW of solar panels with this technology have been installed. They are particularly popular as they can be deployed on flexible 
substrate (Fig. 10) such as stainless steel and titanium sheets. They can also be fabricated on polyimide, but the low temperature of processing $\left(<450^{\circ} \mathrm{C}\right)$ results in lower efficiencies.

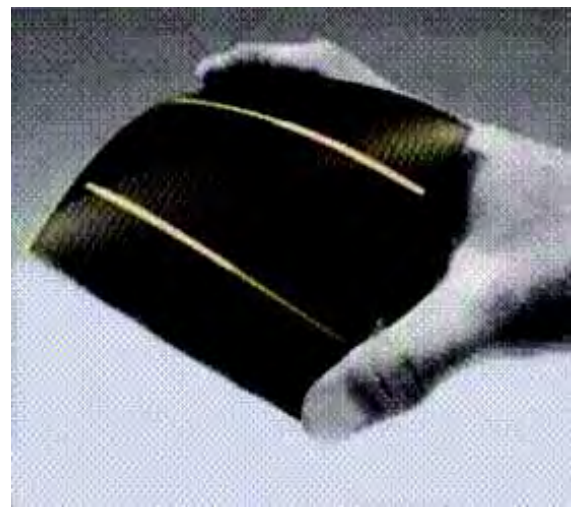

Fig. 10: CIGS is a thin film solar cell that may be fabricated on flexible substrates making it ideal for building integrated PV. Here, a CIGS solar cell from Day Star Technologies, Inc. (01/11/2006) is shown (http:// www.solarserver.com/solarmagazin/newsa2006_01_e. html)

Typical CIGS cells consist of Mo back contact, a $p$-type CIGS absorption layer and doped $\mathrm{ZnO}$ as the transparent conducting oxide (TCO). However, the methods of manufacturing followed by different groups are varied. Broadly, there are three methods of fabrication of the absorption layer. One method is co-evaporation of the elements on heated glass substrate at $600^{\circ} \mathrm{C}$ (usually held below the sources). Modern in-line diagnostics help in getting the right stoichiometry. Another method is to form the metal films and then subject them to selenidization/ sulphurization. The latter may be carried out with hydride gasses $\left(\mathrm{H}_{2} \mathrm{Se} / \mathrm{H}_{2} \mathrm{~S}\right)$ for better control, although toxicity can be an issue. The third method is to deposit the films by wet processes such as electrodeposition/ particulate deposition/solution processing. However, this method does not form as dense a film and efficiencies are usually lower. Usually the first and second methods result in higher efficiencies, but with a larger cost and challenges for large-scale production (Hibberd et al., 2010).

CIGS involving five elements can have many stable phases which are not useful for solar cell purposes. Thus, the process window is small and is a challenge for manufacturing. Moreover, there are limitations on the window layer where $\mathrm{CdS}$ (Cd toxicity is an issue), $\mathrm{ZnS}$ and $\mathrm{InS}$ are explored. Similarly, the doped $\mathrm{ZnO}$ as TCO raises concerns about stability. A few extensive studies on CIGS solar cell technology are Tiwari et al., (2010) and Kodigala (2010), which also highlight the different international groups involved in research, development and production. Moser Baer India Ltd. has undertaken an MNRE-supported project to come up with a manufacturing technology for CIGS solar cells.

One of the biggest challenges posed by CIGS towards terawatt power production is the limited supply of In in earth's crust. There have been attempts to recycle the In from old modules, but more research and development is needed to make this efficient and cost-effective. This has prompted researchers to look for earth-abundant element-based solar cells.

\section{Copper Zinc Tin Selenide/sulphide}

Copper zinc tin selenide/sulphide (CZTS) has evolved as a possible alternative to CIGS solar cells using earthabundant elements. The first solar cells of this type were reported in 1988 (Ito and Nakazawa, 1988). There has been rapid increase in the efficiencies in the last one and half decades. In 1997, 2.3\% efficiency was reported and by 2010, the efficiency had crossed 10\%. In August 2012, IBM, partnering with Solar Frontier, Tokyo Ohka Kogyo (TOK) and DelSolar, announced CZTS solar cell of efficiency up to $11.1 \%$ (http://phys.org/news/2012-08-ibm-efficiencyabundant-material-solar.html). Much of the rapid improvement in these solar cells is due to crosslearning from CIGS. Thus, there is much promise in this technology. Within India, the thin-film solar cell group at NPL has been working on CZTS solar cells along with research activities on CIGS.

\section{Cadmium Telluride}

The first Cadmium telluride (CdTe) solar cells were reported in 1963 (Cusano, 1963), but it was in the 1990s that interest in the technology picked up. Due to some good technological improvements, in the 
middle of the first decade of the twenty-first century by companies such as First Solar, power generated for less than $\$ 1$ a watt from CdTe solar cells was reported. With significant lowering of cost of Si solar cells in the last couple of years, the excitement for CdTe technology in recent years has somewhat diminished.

There are many facets that make CdTe technology attractive. Its band-gap of $1.44 \mathrm{eV}$ at 300 $\mathrm{K}$ is in the region where the Shokley-Queisser efficiency limit will be among the highest. Its absorption coefficient is high and a couple of microns of the material can absorb most of the incident light in the spectrum. As with other II-VI compounds, Cd and Te sublime congruently and the compound CdTe is thermodynamically stable. Thus, it is easy to form stoichiometric CdTe by simple thermal deposition process with high deposition rates of more than 20 microns per minute.

A typical CdTe solar cell is fabricated on a glass substrate (Meyers and Albright, 2000) with the TCO$\mathrm{SnO}_{2}: \mathrm{F}$, followed by an $n$-type window layer of $\mathrm{CdS}$ and the absorption layer of $p$-type CdTe. Finally, the contact is made with $\mathrm{ZnTe}$ or $\mathrm{Cu}$ or $\mathrm{C}$. One big advantage is that the temperature of deposition of the first three layers - TCO, $C d S$ and CdTe of $\sim 600^{\circ} \mathrm{C}$ is the temperature where the glass exits a float line. This advantage to manufacturing has been used to the fullest extent by First Solar and other companies to reduce the cost of production.

In spite of the above advantages, the highest efficiency of CdTe solar cells today are only around $50 \%$ of the Shokley-Queisser limit and the manufacturing efficiencies are around 11-12\%. This can be alleviated only by increasing both the $I_{\mathrm{sc}}$ and the $V_{\text {oc }}$ for these devices.

The $I_{\text {sc }}$ can be improved by increasing absorption of more light in the CdTe absorption layer and not in other parts of the cell. The $\mathrm{SnO}_{2}: \mathrm{F}$ TCO layer and $\mathrm{CdS}$ window layer absorb much of the blue part of the solar spectrum. Attempts have been made to improve this by changing the TCO or by substituting of $\mathrm{CdS}$ with alternative TCOs such as indium tin oxide (ITO) and cadmium stannate. However, they are either costly or too complex to handle. Sulphides of $\mathrm{Zn}$ and In or oxygenated $\mathrm{CdS}$ have been tried for window layers.

The $V_{\text {oc }}$ observed for CdS is more than $200 \mathrm{mV}$ and less than that for GaAs which has a comparable band-gap of $1.42 \mathrm{eV}$. This is primarily due to the low carrier lifetime of a few ns arising from defects as well as grain-boundaries in the polycrystalline $\mathrm{CdTe}$ layer. Crystalline CdTe on the other hand gives minority carrier lifetimes of about $1 \mathrm{~ms}$. However, solar cells in crystalline $\mathrm{CdTe}$ are poorer in performance than in polycrystalline CdTe. This apparent paradox is due to the fact that the grain boundaries may be playing a critical role in the transport of charges and thus help in other aspects of the photovoltaic process. Although in the industry, some empirical solutions are being used and touted to solve the issue, there are no simple or reliable solutions as yet. One needs to understand the role of defects and carrier lifetime in CdTe and see how to increase the latter without compromising on the mobility of the charges (Wolden et al., 2011). One potential solution is to build $p-i-n$ structures, but the control of dopants in CdTe to obtain these structures needs to be mastered.

The toxicity of $\mathrm{Cd}$ is often raised as an issue when considering deployment of CdTe solar cells. However, tests indicate that contamination due to $\mathrm{Cd}$ even during fire hazards or cracked modules are negligible. In fact, it is argued that $\mathrm{Cd}$, which is a byproduct of mining $\mathrm{Zn}$, can be safely sequestered in the solar panels between the glass plates. The manufacturers are also committed to taking back the panels for re-using $\mathrm{Cd}$ at the end of the solar panel lifetime. It will also be useful to re-use the Te which is a rare element of limited supply. On the whole, while CdTe is likely to play a role in the PV technology, much research needs to be carried out before it can take the centre stage. Moreover, the limited availability of Te can be a bottleneck for terawatts of power being generated by CdTe solar cells and this issue has to be addressed. A couple of useful review articles on CdTe technology by Wu (2004) and MoralesAcevedo (2006) are available. 


\section{High Efficiency Solar Cells: GaAs, Multi-junction and Solar Trackers}

Some of the highest efficiencies are achieved by direct band-gap semiconductor solar cells such as GaAs solar cells. These solar cells routinely achieve efficiencies close to $30 \%$ (single junction $-28.8 \%$ by Alta Devices in 2012), while the practical maximum efficiency of Si solar cells is only $25 \%$. Researchers such as Yablonovitch and Atwater have championed the use of these devices (http://www.altadevices.com/ technology-overview.php). However, the GaAs solar cells could end up much more costly to produce.

Another option to increase the efficiency is the multi-junction solar cells, one cell stacked on the other with highest band-gap closer to the light source and smallest band-gap farthest from it (Fig. 11). With two cells, the theoretical Shockley-Queisser maximum efficiency achievable jumps to $42 \%$ and with three junctions, it increases to 49\% (De Vos, 1980). With the highest possible light concentration, the theoretical maximum efficiencies for single, double and triple junction solar cells are 40\%, 55\%, and 63\%, respectively. As seen from the chart in Fig. 7, researchers at Sharp with triple junction, inverted, metamorphic cells and 302 times concentration have managed to achieve $44.4 \%$ efficiency - the highest efficiency solar cells as of 2013).

Besides the higher efficiencies achieved with concentration of light, there is also economic advantage as the cell size can be small while much of the solar panel is covered by concentrating mirrors. Mirror cost per unit area is cheaper than the cost of cells. This approach has been found to be attractive, especially in large area deployment in desert areas with copious direct radiation. One additional requirement of the concentrators is to include trackers in these solar modules (Fig. 12) because the concentrators will not be effective in diffused radiation and are optimal when parallel rays of light fall on them. For the same reasons, these solar panels are not effective in cloudy and foggy conditions and are unlikely to find larger use in medium and small scale deployment - although in drier and predictably sunny weather conditions, they can be economically attractive. One also has to factor the mechanical

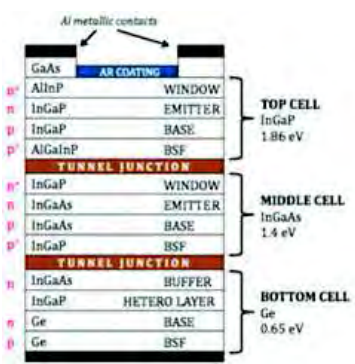

A

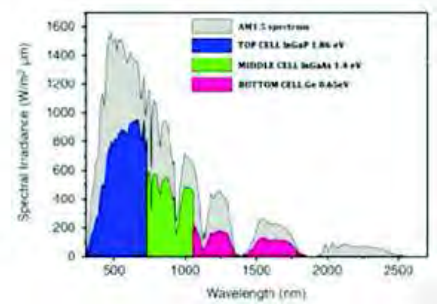

B
Fig. 11: A: An example of a triple-junction solar cell structure with cell junctions formed with Ge, InGaAs and InGaP stacked on top of each other. B: The cell absorbing the blue part of the solar spectrum (InGaP) is on the top facing the incoming radiation, the cell absorbing the green part (InGaAs) is in the middle and the cell absorbing the red part (Ge) is at the bottom of the stack (Yastrebova, 2007)

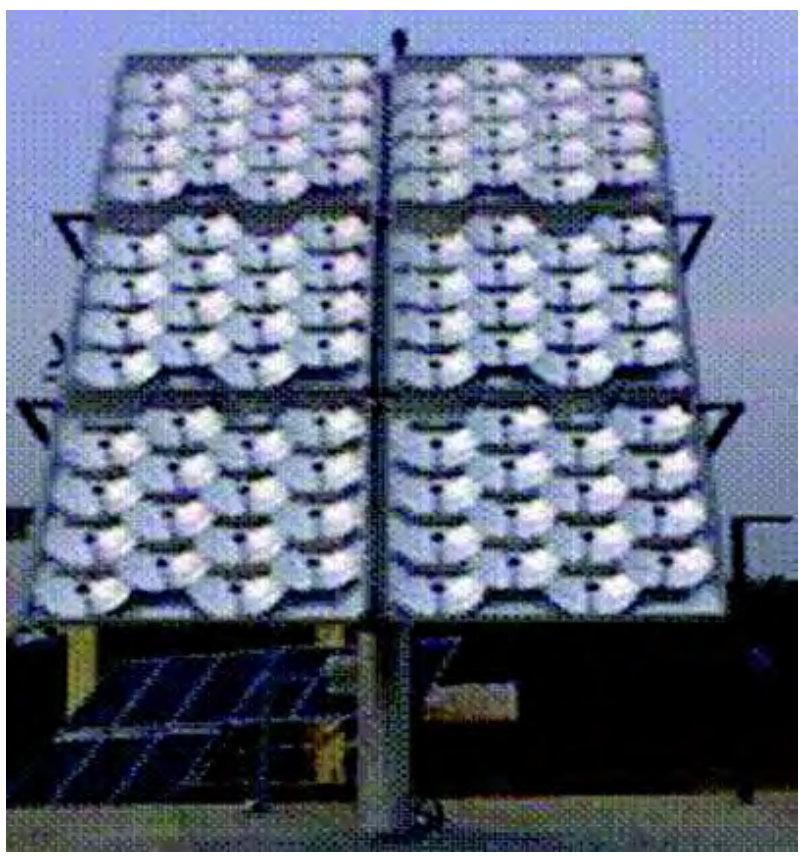

Fig. 12: A $1.2 \mathrm{kWp}$ tracker set up by Moser Baer Photovoltaic Pvt. Ltd. Each of the parabolic mirrors has a high efficiency solar cell located at the focus. A similar tracker has been installed at IIT Kanpur by the company

functioning of the trackers and their maintenance requirement.

\section{Excitonic Solar Cells}

A third generation futuristic technology based solar cells which does not use the classic semiconductor 
$p-n$ junctions has emerged in the last two decades. These are often called "excitonic" solar cells because of the increased role of excitons in the photovoltaic process in these devices. Every electron when it absorbs energy from a photon forms an exciton - an excited electron. This may also be viewed as an electrically neutral packet of energy consisting of a bound electron and hole. In most inorganic semiconductors, at room temperature and above, these excitons almost immediately break up into free charge carrying electrons and holes. This is because their binding energies are typically less than $25 \mathrm{meV}$. In excitonic solar cells, however, the exciton binding energies are of the order of $100 \mathrm{meV}$ and hence, they do not automatically break up into electrons and holes without facilitation. On the other hand, if the electron and hole pair is not formed, the exciton annihilates after some time, often dissipating the energy as heat. Two of the most popular excitonic solar cell technologies which have seen a surge of research activities in the last two decades are DSSC and organic solar cells or organic PV. In the last one year or so, Perovskite solar cells have caught the imagination of researchers and are making rapid progress in terms of the power conversion efficiencies that are achievable with this technology.

\section{Organic Solar Cells (OSC)/organic PV}

The fabrication of OSC devices with bi-layers by C.W. Tang of Eastman Kodak in 1986 (Tang, 1986) opened the floodgates of research activities on the subject. The devices are typically made of either soluble organic material such as polymers or by simple thermal evaporation of "small molecules" such as pthalocyanine of $\mathrm{Cu}, \mathrm{Zn}$ and other metals, pentacene and fullerenes such as $C_{60}$, among others. The latter molecules are not exactly small, but are small in comparison to the gigantic polymers. The simplicity of the low temperature processes involved, amenability to high-throughput processes such as printing, and the abundance of the constituent elements present in organic compounds such as $\mathrm{C}, \mathrm{H}, \mathrm{O}, \mathrm{N}, \mathrm{S}$, etc. make these attractive for large area, large volume and high throughput production - which will increasingly become a critical requirement for PV technologies.
Indeed in the last decade, the progress in this technology, especially in the research domain has been spectacular. The maximum efficiencies have been steadily climbing over the last decade from $3.6 \%$ in 2004 to more than $10 \%$ in 2013 . Higher efficiencies have been pursued by various strategies including newer molecules and device structures. The most popular material for research is poly 3-hexyl thiophene (P3HT) and $(6,6)$-phenyl $C_{60}$ butyric acid methyl ester (PCBM) usually used in a blend form to yield bulk heterojunction solar cells. Many new organic molecules are being routinely synthesized and some have shown promising results. An important breakthrough in the stability of the OSCs has been the fabrication of devices with "inverted structures" (Li et al., 2006). Unlike the regular structures, the inverted structure devices consist of ITO (which is the TCO) as the cathode terminal instead of an anode.

Several groups such as Helaitek in Germany and Yang Yang's group in the University of California at Los Angeles have used small molecules to build the devices. One of the advantages of this approach is inherently the presence of more structured layers of the organic semiconductor and the ease of forming tandem solar cells by stacking cells which absorb different parts of the solar spectrum to achieve higher efficiencies.

While significant progress has been made in the efficiency and stability of OSCs, there is still much to be covered before this technology can be hoped to replace established technologies such as silicon PV. Efficiencies above $15 \%$ will make this technology competitive. More importantly, the stability of these devices has to improve. Some companies such as Konarka Technologies, Inc. have earlier demonstrated stability for three years (http://www.swissphotonics. net/libraries.files/Brabec.pdf, slide 25). This might be adequate for some applications, especially disposable electronics. However, for wider power generation application, stabilities of more than a decade will be necessary.

The promise of this technology, however, is the ease with which the OSCs can be fabricated from a wide variety of substrates such as glass, paper, cloth, steel, etc. (Fig. 13). These solar cells are also 

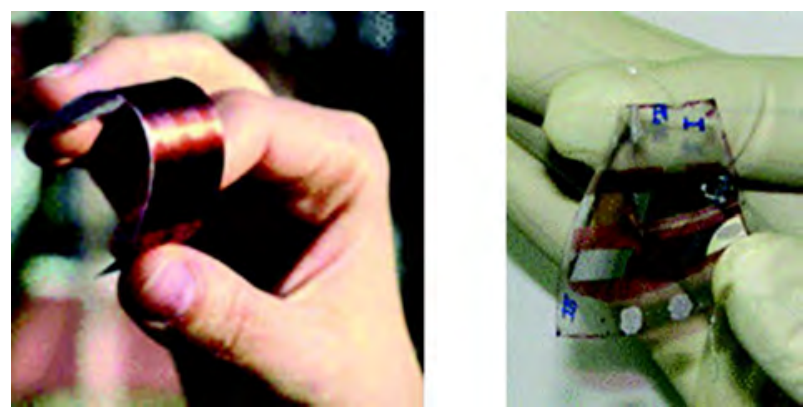

Fig. 13: (A) OSC printed on paper at Chemnitz University of Technology, Germany (Hübler et al., 2011); (B) OSC fabricated on flexible polyethylene terephthalate (PET) at IIT Kanpur(Dembla, 2009)

amenable to novel applications such as transparent solar cells that could be used on windows - it will allow visible light, but harness portions of the solar spectrum outside the visible region to generate power. While no commercial products are widely available with organic PV technologies - there exist some demonstration products - the strength of this technology will be its low cost, ease of use with a variety of substrates, abundance of the material needed to fabricate the main device and the potential for environment-friendly production and recycling after the product lifetime.

Owing to the promise and ease of fabrication, a large number of research groups around the world are working in the area of OSC. Indeed, the number of research-related publications for this technology is among the highest. In India too, there are a number of groups working in this area. IIT Kanpur, IIT Bombay, Indian Association for the Cultivation of Science in Calcutta, Jawaharlal Nehru Centre for Advanced Scientific Research in Bangalore, National Physical Laboratory in New Delhi, National Chemical Laboratory in Poona and many other institutions are conducting state-of-the-art research in this field. Many private institutions such as PSG Institute of Advanced Studies in Coimbatore are also pushing the frontiers of research by exploring OSC on flexible substrates. Due to the large strength of research activity in this area in India, with right coordination, this futuristic area of technology can be the one where Indian researchers and industries can excel.

\section{Dye-sensitized Solar Cells}

Dye-sensitized solar cells (DSSCs), which are based on the photo-electrochemical effect, were first reported in 1991 by O'Regan and Grätzel (O'Regan and Grätzel, 1991). These cells are also often referred to as Grätzel cells after the name of the inventor. Within a few years of DSSC invention, researchers in Prof. Grätzel's group managed to build solar cells with $11 \%$ efficiency.

DSSC uses metallo-organic dyes molecules adsorbed to a mesoporous titania nanoparticle films. Gaps between the particles are filled with an electrolyte and a plantinized electrode is provided. When light gets absorbed in the dye, an exciton is created. This exciton transfers its electron to the $\mathrm{TiO}_{2}$ molecule at the dye-particle interface. The electron makes its way through the $\mathrm{TiO}_{2}$ film to the photoelectrode. It then completes the circuit by doing external work and returning to the platinized electrode to reduce a redox couple in the electrolyte. The reduced ion makes its way to the dye molecule with the positively charged hole and regenerates the molecule.

DSSC technology has found application as chargers for portable electronics. The various colours in which these cells are available as well as the possibility of semi-transparent cells make them attractive for BIPV. One of the main challenges faced by this technology is the inability to increase the power conversion efficiency beyond $11 \%$ in the last many years. The material system of Ru-based dye, photoanode and iodine-based redox couple in the electrolyte has not changed and there is little room for improvement. Typically, modules of less than 100 $\mathrm{cm}^{2}$ are built as the series resistances can become too high, bringing down the efficiency. By far, the biggest challenge is in the encapsulation of these devices and their lifetimes. While properly encapsulated devices have shown promise of more than a decade of lifetime, devices made on plastic typically show lifetimes of a couple of years. Attempts to replace the liquid electrolyte with gels or solid electrolyte have not been very successful as the efficiencies drop. 
This is a promising technology in the long term, but is awaiting research breakthroughs in dyes, photoanode and electrolyte. The simplicity of processing makes it amenable for large volume and high throughput production. A number of research groups within India are funded for research activities in this technology and have been contributing to the understanding and innovations in this technology, notably at National Chemical Laboratory in Poona, IIT Delhi, Cochin University of Science and Technology, Indian Association for the Cultivation of Science in Calcutta and many others.

\section{Perovskite Solar Cells}

Typically, the perovskite material used for solar cells is a methyl ammonium tin or lead halide. The perovskite-based meso-super-structured cells (MSSCs) which have evolved from DSSCs have in the last year made rapid progress in terms of the power conversion efficiency that they are able to achieve but new structures are continuously being explored (Green et al., 2014). Building upon the experience of DSSC, efficiencies of more than $12 \%$ and $V_{\text {oc }}$ of more than $1.1 \mathrm{~V}$ have been fabricated. $\mathrm{A} \mathrm{CH}_{3} \mathrm{NH}_{3} \mathrm{PbI}_{3-}$ ${ }_{x} \mathrm{Cl}_{\mathrm{x}}$-based solar cell with the maximum temperature during device fabrication no higher than $150^{\circ} \mathrm{C}$ and a power conversion efficiency of more than $15.6 \%$ has been reported by Wang et al. (2014) opening up the possibility of fabrication on flexible substrates and large volume production processes as in printing. However, issues of device stability and presence of lead in the device will have to be addressed in the coming years. Whether this technology will overshadow all other technologies is too early to tell, but the rapid progress and promise this technology is showing through published results in less than five years indicates that perovskite solar cells may have an important role to play in PV power generation in the coming years (Green et al., 2014).

There are a number of other material systems and device structures that are being explored for solar cell application such as cuprous oxide, pyrite, quantum dot solar cells, etc. Unless some major breakthroughs are achieved in future, the above discussed technologies will be the pertinent players for power generation and we have restricted the discussion to those.

\section{Government Initiatives}

Internationally, it is seen in the last one and half decades that government initiatives have helped propel PV power generation to centre stage - the prime example being that of Germany. Even with poor sunshine as compared to many other countries across the world, it has become the leading consumer of PV technology. This has been possible because of wellthought out government initiatives and subsidies to promote PV for power generation. Recent reports indicate that in July 2013, 5.1 TWh has been generated from PV which exceeds the energy generated from wind ( $5 \mathrm{TWh}$ ). Germany is well on its way to generate more than $80 \%$ of its power from renewable sources, including PV (http://thinkprogress.org/ climate/2013/ 08/22/2508191/germany-solar-generation-record/).

Governments in most European countries and the Far East too have been promoting power generation from renewables, including PV. The Chinese government has provided immense push and subsidies to make the country the leader in PV manufacturing today. In the USA, in recent years, the federal government has been promoting research, development and production of renewable technologies including PV through the SunShot Inititiave (http://www1.eere.energy.gov/solar/ sunshot/). Various states in the USA such as California have already been in the forefront of promoting power generation with PV resulting in widespread adoption of the technology. Almost all developed and industrial countries are giving importance to using $\mathrm{PV}$ for power generation to varying degrees.

The Government of India too has implemented a clear "National Action Plan on Climate Change". within this "National Action Plan", eight "National Missions" have been identified. One of the national missions is the "National Solar Mission" which was formally launched on 11 January 2010. This mission clearly provides a quantitative and qualitative target that the nation needs to achieve (see Box 1). One of the goals is deployment of $20 \mathrm{GW}$ of solar power by 2022. Another goal is to deploy 20 million solar lighting 


\section{Box 1. Mission targets as specified in the National Solar Mission}

(Announced on 23/11/2009; Launched 11/1/2010)

- To create an enabling policy framework for the deployment of 20,000 MW of solar power by 2022.

- To ramp up capacity of grid-connected solar power generation to $1000 \mathrm{MW}$ within three years by 2013; an additional $3000 \mathrm{MW}$ by 2017 through the mandatory use of the renewable purchase obligation by utilities backed with a preferential tariff. This capacity can be more than doubled reaching 10,000 MW installed power by 2017 or more, based on the enhanced and enabled international finance and technology transfer. The ambitious target for 2022 of 20,000 MW or more, will be dependent on the "learning" of the first two phases, which if successful, could lead to conditions of grid-competitive solar power. The transition could be appropriately up-scaled, based on availability of international finance and technology.

- To create favourable conditions for solar manufacturing capability, particularly solar thermal for indigenous production and market coordinatorship.

- To promote programmes for off-grid applications, reaching $1000 \mathrm{MW}$ by 2017 and $2000 \mathrm{MW}$ by 2022.

- To achieve 15 million sq. metres solar thermal collector area by 2017 and 20 million by 2022 .

- To deploy 20 million solar lighting systems for rural areas by 2022.

systems for rural areas by 2022. These goals and directions have given a shot in the arm to solar PV research, development, manufacturing and deployment. Much effort is required if the targets are to be reached and the country has to withstand, and if needed overcome, any adverse effects of international economic forces.

The MNRE mainly responsible for promoting PV in India has rolled out many programmes to promote PV activities in line with the National Solar Mission (http://www.mnre.gov.in/solar-mission/jnnsm/ introduction-2/). Similarly, Department of Science and Technology (DST) has also given the research an impetus with its Solar Energy Research Initiative (SERI) under which many research programmes across the country as well as international collaborations are supported (http://www.dst.gov.in/ scientific-programme/t-d-solar-energy.htm). Many other ministries and government departments including Ministry of Rural Development, Ministry of Power and Ministry of Communication Information
Technology (especially, DeitY - Department of Electronics and Information Technology) have also promoted PV activities through various existing projects where it is appropriate. The policies of the Indian government and intent of the various ministries have been conducive in the promotion of PV technology for power generation.

One major initiative in India is worth mentioning here. As announced by the Press Information Bureau of Government of India, Ministry of Science \& Technology on 29 August 2013: "CSIR's Solar Energy Initiative - Technologies and Products for Solar Energy Utilization through Networks (TAPSUN) has been conceptualized as a mega programme in partnership with Ministry of New and Renewable Energy. It is being implemented with a number of complementary approaches. The programme has created network of research institutes, academia and industry with an objective to integrate various components of technology development. The programme will play a transformational role in bringing 
the benefits of solar energy to the people of India." Promotion of PV for power generation is an integral part of the TAPSUN programme and has been shaping up as per plan in the last two and half years.

\section{Implementation of Solar PV in India}

The promotion of PV for power generation needs to be undertaken over short, medium and long terms. Ideas that emerged during various meetings and discussions with experts working in the field are compiled here.

\section{Short-term (Three-year Time Frame) Goals}

(i) Emphasis should be given to the use and deployment of crystalline silicon solar modules which are time tested and reliable.

(ii) Identify areas of chronic power shortage and deploy small and medium PV systems in those areas. The economy in many urban and suburban pockets is driven by the polluting dieselpowered generators and the power available is costly when compared to equivalent $\mathrm{PV}$ power cost - and hence, the effort should be economically viable as well. With the right economic packages, government has to undertake this on a war footing.

(iii) The government should hasten to implement clearly defined policies and legal protection to promote BIPV. With proper incentives in place and smoother implementation, the building owner will ensure proper maintenance and running of the facility.

(iv) Encourage and provide incentives to all industries to set up auxiliary PV systems to supplement power from the grid.

(v) Encourage PV deployment on government buildings, roads, bus-stops, shelters and other such places already being used by humans. In some states such as Gujarat, canal carrying irrigation water are covered with PV panels, as a result of which the space is maximized, cells are kept cool and water loss due to evaporation is minimized. (vi) Encourage researchers and industry to develop a robust power electronic system specific to the Indian grid and local conditions.

\section{Medium-term (Three to Eight Year Time Frame) Goals}

(i) Set up foundries for the manufacture of solar grade silicon wafers. Build fabrication plants for silicon solar cells. In the short run, there is bound to be competition and loss due to the efficient and well-established Chinese solar industry. However, as India's power needs soar, indigenous systems can play a critical role if they are ready ahead of time.

(ii) Invest in batteries and thermal storage for medium-term storage and fuel cells and hydel storage for long-term storage. Some form of long-term storage is imperative to make solar power attractive for year-round operations and to withstand the vagaries of weather conditions. Hydel storage might be possible in regions near high mountainous locations. PV in conjunction with other renewables such as biofuels and solar thermal should be promoted.

(iii) Build reliable database and models to be able to predict weather for shorter time intervals, but as far in advance as possible. This will be critical to be able to use PV for power generation, especially if the generated power is directly fed to the grid.

(iv) Encourage with contests and other incentives, innovations and development of consumer products which have application unique to Indian conditions.

(v) Train manpower through existing and new institutions. The National Centre for Photovoltaic Research and Education at IIT Bombay is a good example of such an effort. More such centres around the country should be established.

\section{Long-term (Beyond Eight Years) Goals}

(i) Encourage initiatives with long-term and challenging research goals in silicon and other 
areas of PV technologies that will encourage competitiveness in manufacture in the coming decades

(ii) Use hybrid systems with renewable technologies - solar, thermal, wind, biomass, etc. - to ensure stable power supply, synergizing the strengths of the different technologies and mitigating their disadvantages.

(iii) Actively promote research in futuristic technologies with good environmental benefits such as OSC, DSSC and Perovskite solar cells and make India a powerhouse of these technologies. These technologies might be able to mitigate any potential environmental harm arising out of large-scale manufacture and use of PV cells and modules. They will also help create production methods that are distributed leading to more sustainable economic development.

\section{Conclusions}

Energy needs are only going to increase in the coming decades. For countries such as India, the future

\section{References}

Atwater H A and Polman A (2010) Plasmonics for improved photovoltaic devices Nat Mater 9 205-213

Carlson D E and Wronski C R (1976) Amorphous silicon solar cell Appl Phys Lett 28 671-673

Chapin D M, Fuller C S and Pearson G L (1954) A new silicon p$\mathrm{n}$ junction photocell for converting solar radiation into electrical power $J$ Appl Phys 25 676-677

Cusano D A (1963) CdTe solar cells and photovoltaic heterojunctions in II-VI compounds Solid State Electron 6 217-218

De Vos A (1980) Detailed balance limit of the efficiency of tandem solar cells J Phys D: Appl Phys 13 839-846

Dembla A (2009) P3HT: PCBM bulk heterojunction solar cells on flexible PET substrates. M. Tech. Thesis, Indian Institute of Technology Kanpur, Kanpur, pp 24-36

Goetzberger A, Hebling C and Schock H W (2003) Photovoltaic materials, history, status and outlook Mater Sci Eng $R \mathbf{4 0}$ $1-46$ energy requirements in 50 years will be much more than the current requirement. Thus, sustainable energy harvesting with PV is not just attractive, but is inevitable. There are many PV technologies available today. In the short run, silicon-based technologies are the best bet. However, in the coming decades, more attractive eco-friendly technologies with the promise of shorter energy payback time such as OSC and DSSC need to be explored. The Indian government departments, government labs, academia and the industry need to come together and continue to propel $\mathrm{PV}$ as one of the main means of power generation.

\section{Acknowledgements}

I thank my colleagues and mentors with whom I received a chance to learn about PV technologies in various forums in the last decade. Much of what I have described above is a result of that learning. I especially thank Collin Wolden for the discussions when he was in India. His review article (Wolden et $a l ., 2011$ ) is an excellent supplement for those who want to learn more about the current status of PV technologies.

Green MA (1999) Limiting efficiency of bulk and thin-film silicon solar cells in the presence of surface recombination Prog Photovolt: Res Appl 7 327-330

Green MA, Ho-Baillie A and Snaith H J (2014) The emergence of Perovskite solar cells Nature Photon 8 506-514

Hänni S, Bugnon G, Parascandolo G, Boccard M, Escarré J, Despeisse M, Meillaud F and Ballif C (2013) Highefficiency microcrystalline silicon single-junction solar cells Prog Photovolt: Res Appl 21 821-826

Hibberd C J, Chassaing E, Liu W, Mitzi D B, Lincot D, and Tiwari AN (2010) Non-vacuum methods for formation of $\mathrm{Cu}(\mathrm{In}, \mathrm{Ga})(\mathrm{Se}, \mathrm{S})_{2}$ thin film photovoltaic absorbers Prog Photovolt: Res Appl 18 434-452

Hilali M M., Rohatgi A and Asher S (2004) Development of screen-printed silicon solar cells with high fill factors on 100 Ù/sq emitters IEEE Trans Electron Dev 51 948-955

Hirst L C and Ekins-Daukes N J (2011) Fundamental losses in solar cells Prog Photovolt: Res Appl 19 286-293

Hoffert M I, Caldeira K, Jain A K, Haites E F, Harvey L D D, 
Potter S D, Schlesinger M E, Schneider S H, Watts R G, Wigley T M L and Wuebbles D J (1998) Energy implications of future stabilization of atmospheric $\mathrm{CO}_{2}$ content Nature 395 881-884

Hübler A, Trnovec C, Zillger T, Ali M, Wetzold N, Mingebach M, Wagenpfahl A, Deibel C and Dyakonov V (2011) Printed paper photovoltaic cells Adv Energy Mater 1 10181022

Ito K and Nakazawa T (1988) Electrical and optical properties of stannite-type quaternary semiconductor thin films Jpn J Appl Phys 27 2094-2097

Kazmerski L L, White F R and Morgan G K (1976) Thin-film $\mathrm{CuInSe}_{2} / \mathrm{CdS}$ heterojunction solar cells Appl Phys Lett 29 268-270

Kodigala S R (2010) $\mathrm{Cu}\left(\mathrm{In}_{1-\mathrm{x}} \mathrm{Ga}_{\mathrm{x}}\right) \mathrm{Se}_{2}$ based thin film solar cells. In: Thin Films and Nanostructures 35, Academic Press

Li G, Chu C-W, Shrotriya, Huang V J and Yang Y (2006) Efficient inverted polymer solar cells Appl Phys Lett 88253503 (3 pages)

Meyers P V and Albright S P (2000) Technical and economic opportunities for CdTe PV at the turn of the millennium Prog Photovolt Res Appl 8 161-169

Morales-Acevedo A (2006) Thin film CdS/CdTe solar cells: Research perspectives Sol Energy 80 675-681

Mulligan W and Swanson R (2003) High-Efficiency, One-Sun Cell Processing Proc 13th NREL Crystalline Silicon Workshop Vail Colorado 30-37

O'Regan B and Grätzel M (1991) A low-cost, high-efficiency solar cell based on dye-sensitized colloidal $\mathrm{TiO}_{2}$ films Nature 353 737-740

Rohatgi A, Meiera D L, McPhersona B, Okb Y-W, Upadhyaya A D, Laib J-H and Zimbardi F (2012) High-throughput ionimplantation for low-cost, high-efficiency silicon solar cells International Conference on Materials for Advanced Technologies 2011, Symposium O, Energy Proc 15 10-19

Roschek T, Repmann T, Müller J, Rech B and Wagner H (2002) Comprehensive study of microcrystalline silicon solar cells deposited at high rate using $13.56 \mathrm{MHz}$ plasma-enhanced chemical vapor deposition J Vac Sci Technol A $20492-498$

Rowlette P C and Wolden C A (2009) Digital Control of $\mathrm{SiO}_{2}-$ $\mathrm{TiO}_{2}$ Mixed-metal oxides by pulsed PECVD ACS Appl. Mater Int. 1 2586-2591
Shockley W and Queisser H J (1961) Detailed balance limit of efficiency of $p$ - $n$ junction solar cells J Appl Phys 32 510519

Solanki C S (2011) Solar Photovoltaics Fundamentals, Technologies and Applications. PHI Learning Pvt. Ltd. pp 147-152

Staebler D L and Wronski C R (1977) Reversible conductivity changes in discharge-produced amorphous silicon Appl Phys Lett 31 292-294

Swinehert D F (1962) The Beer-Lambert Law J Chem Edu 39 333-335

Sze SM (1991) Physics of Semiconductor Devices, Chapter 14. Wiley Eastern

Taguchi M, Sakata H, Yoshimine Y, Maruyama E, Terakawa A, Tanaka M and Kiyama S (2005) An approach for the higher efficiency in the HIT cells Proc $31^{\text {st }}$ IEEE Photovoltaic Specialists Conf, Orlando Florida 866-871

Tang C W (1986) Two-layer organic photovoltaic cell Appl Phys Lett 48 183-185

Tiwari A N, Lincot D and Contreras M (Editors of the Issue) (2010) The time for CIGS Prog Photovolt: Res Appl 18 389

Wang J T-W, Ball J M, Barea E M, Abate A, Alexander-Webber J A, Huang J, Saliba M, Mora-Sero I, Bisquert J, Snaith H J and R J (2014) Low-temperature processed electron collection layers of graphene/ $\mathrm{TiO}_{2}$ nanocomposites in thin film perovskite solar cells Nano Lett 14 724-730

Wolden C A, Kurtin J, Baxter J B, Repins I, Shaheen S E, Torvik J T, Rockett A A, Fthenakis V M and Aydil E S (2011) Photovoltaic manufacturing: Present status, future prospects and research needs J Vac Sci Technol A 29030801 (16 pages)

Wu X (2004) High-efficiency polycrystalline CdTe thin-film solar cells Sol Energy 77 803-814

Yastrebova N V (2007) High-efficiency multi-junction solar cells: Current status and future potential http://sunlab.eecs. uottawa.ca/wp-content/uploads/2014/pdf/HiEfficMjScCurrStatusFuturePotential.pdf

Zhao J, Wang A, Green MA and Ferrazza F (1998) Novel 19.8\% efficient "honeycomb" textured multicrystalline and $24.4 \%$ monocrystalline silicon solar cells Appl Phys Lett 73 19911993. 